\title{
Correction to: Molecular Insights into Oral Malignancy
}

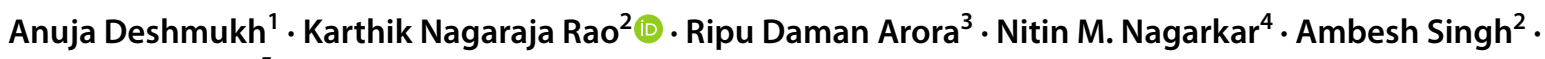 \\ Om Shree Shetty ${ }^{5}$
}

Published online: 28 October 2021

(C) Indian Association of Surgical Oncology 2021

\section{Correction to: Indian Journal of Surgical Oncology https://doi.org/10.1007/s13193-021-01431-4}

Dr. Anuja Deshmukh and Dr. Om Shree Shetty had played a pivotal role in the development of the Manuscript, their names were inadvertently missed. It is imperative to include both as the Authors.

This is being corrected in this publication.

Publisher's Note Springer Nature remains neutral with regard to jurisdictional claims in published maps and institutional affiliations.

The online version of the original article can be found at https:// doi.org/10.1007/s13193-021-01431-4

Anuja Deshmukh

anuja327@gmail.com

Karthik Nagaraja Rao

Karthik.nag.rao@gmail.com

Ripu Daman Arora

neelripu@gmail.com

Nitin M. Nagarkar

directoroffice@aiimsraipur.edu.in

Ambesh Singh

ambesh.singh26@gmail.com

Om Shree Shetty

omshreens@gmail.com
1 Department of Head and Neck Surgery, Tata Memorial Hospital, Mumbai, India

2 Department of Head and Neck Oncology, All India Institute of Medical Sciences, Raipur, India

3 Department of Otolaryngology and Head Neck Surgery, All India Institute of Medical Sciences, Raipur, India

4 All India Institute of Medical Sciences, Raipur, India

5 Department of Molecular Pathology, Tata Memorial Hospital, Mumbai, India 